\title{
DESIGN E EDUCAÇÃO: ABORDAGENS METODOLÓGICAS E SUAS DIALOGIAS
}

\author{
Janaína Campos Branco \\ Universidade Federal de Pernambuco \\ janacampos.branco@gmail.com \\ Gregorio Bacelar Lameira \\ Universidade Federal de Pernambuco \\ gregbacelar@gmail.com \\ Eva Rolim Miranda \\ Universidade Federal de Pernambuco \\ evarolim@gmail.com
}

Resumo: Este artigo visou demonstrar os resultados de um diálogo metodológico proposto entre três pesquisas que tem como base teórica o design e a educação. Para isso, apresentou-se os três estudos, suas problemáticas, objetivos e os fundamentos lógicos. A fim de uma melhor visualização das abordagens escolhidas para cada trabalho, foi utilizado como referência o quadro com a rede de características e suposições fundamentais, adaptado de Morgan \& Smircich (1980), que tange o debate sujeito/objeto dentro das Ciências Sociais. Por fim, as tríades teóricas de cada uma das pesquisas foram confrontadas e expostas em um diagrama a fim de clarificar a visualização de seus diálogos.

Palavras-chave: design, educação, abordagens metodológicas

\begin{abstract}
This article aims to demonstrate the results of a methodological dialogue proposed between three research studies, for which the theoretical bases are design and education. For this, three studies are presented, together with their problems, objectives and rationale. In order to provide a better visualization of the approaches chosen for each research, our reference will be a chart with the network of characteristics and basic assumptions, adapted by Morgan \& Smircich (1980), regarding the debate subject/object within social science. Finally, the theoretical triads of each of research are compared and displayed in a diagram in order to clarify the viewpoint of their dialogues.
\end{abstract}

Keywords: design, education, methodological approaches

\section{INTRODUÇÃO}


Diante de uma sociedade em constante transformação e sendo a educação responsável por grandes mudanças sociais, a necessidade de adequações no processo de ensino-aprendizagem torna-se cada vez mais urgente. Na atualidade, o design é visto como uma ciência em construção, multidisciplinar que consegue dialogar e participar de diversos processos de transformação nas mais distintas áreas. Desse modo, o design ainda está sendo visto como mediador do conhecimento no campo pedagógico e pesquisas estão sendo desenvolvidas acerca de formas nas quais o design pode colaborar com a educação.

Neste artigo discriminaremos duas dessas pesquisas. A primeira da "pesquisadora 1", que propôs anteriormente em seus estudos um diálogo entre metodologias de design e de arte/educação, e agora busca a aplicação dessa união em sala de aula, onde o artefato educacional utilizado na pesquisa será o assemblage. A segunda do "pesquisador 2", que propõe uma análise, a partir de experimentos que envolvem o uso de objetos educacionais digitais (OEDs), inseridos em hiperlivros didáticos baseando-se em aspectos relacionados à organização e à compreensão da informação por parte dos alunos. Visa, assim, entender quais os benefícios e prejuízos os OEDs trazem no processo de ensino-aprendizagem e quais melhorias podem ser adotadas.

A pesquisadora Cristina Portugal, motivada pelos materiais didáticos utilizados em sala de aula e da inovação do ensino por meio do Design, dedicou dois anos em uma pesquisa de pós-doutoramento que culminou no livro Design, Educação $e$ Tecnologia, publicado pela Editora Rio Books, onde propõe um diálogo acerca das três áreas que compõe o título da obra.

Dessa forma, este artigo tem por objetivo promover a explanação dos três trabalhos acima citados e do diálogo entre eles.

\section{DESIGN E ARTE/EDUCAÇÃO}

\subsection{Design e Arte/Educação: Uma Intersecção Metodológica}

O título desse tópico foi utilizado como tema do trabalho de conclusão da graduação em Design da pesquisadora 1, que buscou fundamentar teoricamente a presença do design nas escolas e como isso tem acontecido em parceria com a arte/educação. Foram apresentadas duas metodologias (de design e de arte/educação) e a teoria da atividade, que permeia essa união. Durante o trabalho de graduação foi apresentada também uma sugestão que concretiza essa união na prática de sala de aula: as assemblages.

Através da comparação (Quadro 1) entre a metodologia de arte/educação (abordagem triangular proposta por Ana Mae Barbosa, 1998) e a metodologia de Design (Design Industrial desenvolvida por Bernd Löbach, 2001) - fomentada pela Teoria da Complexidade de Edgar Morin, 1991) - pôde-se entender os aspectos nos quais as áreas afins do design e da arte/educação estabelecem relações de oposição, complementaridade ou de concorrência.

Foi, portanto, por intermédio do auxílio e da fundamentação propiciadas pelo pensamento complexo, que se chegou a averiguação de que as metodologias de Design e Arte/Educação em questão são complementares, embora existam pequenas 
divergências em algumas características específicas das mesmas - dito de outro modo, as divergências acabam por alimentar as complementaridades entre as metodologias acima referidas em meio às lacunas geradas.

Quadro 1 - Quadro explicativo e comparativo acerca da Abordagem Triangular (Barbosa) e da Metodologia de Design Industrial (Löbach).

\begin{tabular}{|c|c|c|c|}
\hline $\begin{array}{l}\text { Abordagem } \\
\text { triangular }\end{array}$ & Método & $\begin{array}{l}\text { Metodologia de } \\
\text { Löbach }\end{array}$ & Método \\
\hline Contextualizar & $\begin{array}{l}\text { Prática artística baseada na } \\
\text { análise do contexto no qual a } \\
\text { obra está inserida, fazendo com } \\
\text { que a arte seja compreendida } \\
\text { como manifesto sociocultural. }\end{array}$ & $\begin{array}{l}\text { Fase de } \\
\text { preparação }\end{array}$ & $\begin{array}{l}\text { Análise e compreensão do } \\
\text { contexto sociocultural e } \\
\text { econômico, no qual o } \\
\text { problema está inserido, } \\
\text { através da análise e coleta de } \\
\text { informações. }\end{array}$ \\
\hline - - - - - & - - - - - & Fase de Geração & $\begin{array}{l}\text { Análise e escolha dos } \\
\text { métodos para solução do } \\
\text { problema, assim como } \\
\text { geração de alternativas. }\end{array}$ \\
\hline Apreciar & $\begin{array}{l}\text { Questionamento sobre as } \\
\text { escolhas dos artistas, por } \\
\text { intermédio, inclusive de uma } \\
\text { releitura das obras, o que leva o } \\
\text { observador a tornar-se um } \\
\underline{\text { crítico baseado em parâmetros e }} \\
\text { teorias. }\end{array}$ & $\begin{array}{l}\text { Fase de } \\
\text { Avaliação }\end{array}$ & $\begin{array}{l}\text { Avaliação de modo crítico } \\
\text { acerca das alternativas } \\
\text { geradas, baseada em teorias, } \\
\text { parâmetros e no contexto no } \\
\text { qual o problema está } \\
\text { inserido. }\end{array}$ \\
\hline Produzir & $\begin{array}{l}\text { Concretizar todas as } \\
\text { informações e conhecimentos } \\
\text { adquiridos através da releitura e } \\
\text { contextualização, pondo em } \\
\text { prática conhecimentos acerca de } \\
\text { técnicas e materiais. }\end{array}$ & $\begin{array}{l}\text { Fase de } \\
\text { Realização }\end{array}$ & $\begin{array}{l}\text { Concretizar a solução do } \\
\text { problema através da análise } \\
\text { do contexto no qual o } \\
\text { problema está inserido, da } \\
\text { escolha dos métodos e da } \\
\text { releitura das alternativas. }\end{array}$ \\
\hline
\end{tabular}

Fonte: Adaptado de Bernd Löbach (2001)

\subsubsection{Assemblages: Ferramenta complexa e multidisciplinar, aliada do design e da arte/educação nas escolas}

As assemblages utilizam os mesmos fundamentos da Proposta Triangular e da Metodologia de Design Industrial: Contextualização, Releitura e Produção. Elas podem também ser tratadas como ferramentas que auxiliam o ensino de Arte/Educação nas escolas, já que se trata de uma expressão artística que incorpora características advindas tanto da Proposta Triangular de Ana Mae Barbosa (1998), quanto da Metodologia de Design Industrial desenvolvida por Löbach (2001).

A revista virtual 'Nova Escola'1 aponta outra vantagem relacionada ao uso das assemblages no contexto da sala de aula que é a possibilidade da experimentação, da apreciação e do estudo "já que a obra e todo o percurso para elaborá-la são um desafio constante para os alunos: encontrar soluções - estéticas e ao mesmo tempo lúdicas - para os problemas de construção com que eles se deparam".

1 http://revistaescola.abril.com.br/fundamental-1/assemblage-arte-reunir-objetos-diversos-contarhistorias-639039.shtml. 
Nesses pontos, no contexto dos assemblages, o Design e a Arte/Educação dialogam em sala de aula, pois, através da busca por soluções dos problemas (característica marcante do Design), da estética (encontrada tanto na Arte-Educação, quanto no Design) e do lúdico (típico da Arte/Educação) há uma união harmônica, útil e ainda pouco explorada do Design e da Arte/Educação.

\subsection{Design e Arte/Educação: Uma nova perspectiva para o ensino das artes visuais nas séries iniciais do ensino fundamental}

A realidade do ensino de arte comumente observada em salas de aula do município de Garanhuns-PE no último ano diverge de propostas pautadas por arte/educadores brasileiros, como da Abordagem Triangular desenvolvida por Ana Mae Barbosa (1998), observando que em sala de aula, não são utilizadas teorias e métodos que poderiam facilitar o processo de ensino-aprendizagem para todos os personagens envolvidos.

Por intermédio da Teoria da Atividade de Alexei Leontiev (1992) e Teoria da Complexidade de Edgar Morin (1991), a união da Proposta Triangular do ensino da Arte de Ana Mae Barbosa (1998) e métodos de Design Industrial do alemão Bern Löbach (2001), é sugerido que a relação entre Arte/Educação e Design pode contribuir no processo de ensino-aprendizagem das artes visuais, considerando todo o sistema de trabalho e desenvolvendo nos alunos novas habilidades, técnicas e métodos de criação e produção.

Essa união entre teorias, proposta e metodologia de Arte/Educação e Design, baseia-se num questionamento acerca do modo pelo qual a relação entre ArteEducação e Design contribui para o processo de ensino-aprendizagem dos alunos do 30 ano do ensino fundamental de uma escola municipal do município de Garanhuns, em Pernambuco, e como proporcionar aos alunos uma imersão no universo do Design desde as séries iniciais.

O confronto entre a Proposta Triangular e a metodologia de Design escolhida (metodologia de Löbach) por intermédio das Teorias da Atividade e da Complexidade só tende a enriquecer ambas as áreas, visto que, apesar das metodologias abordadas possuírem muitos pontos em comum, seus trajetos teórico-metodológicos tiveram desenvolvimentos e aplicações distintos e é nestas brechas que pode ocorrer o processo de colaboração mútua.

Baseada na união de similaridades entre metodologias de Arte/Educação (Abordagem Triangular do Ensino da Arte) e de Design (Metodologia de Design Industrial), a pesquisa visou buscar ferramentas metodológicas e instrumentos de Design que contribuíssem para o processo de ensino das artes visuais através das Teorias da Atividade e da Complexidade.

\section{OBJETOS EDUCACIONAIS DIGITAIS NO PROCESSO DE ENSINO-APRENDIZAGEM: IMPACTOS NO DESEMPENHO ESTUDANTIL}

A utilização de tecnologia como suporte didático, que auxilia na aprendizagem de alunos em diferentes níveis escolares não é algo recente. No entanto, sua evolução vem desafiando o ensino tradicional - aquele que se apropria quase que exclusivamente do uso de quadro, giz e livros impressos - trazendo a busca por novas formas de adaptação, que caminhe em sincronia com os novos dispositivos utilizados 
em sala de aula. Isso resultaria possivelmente na potencialização da transmissão de conteúdos de difícil aceitação/entendimento ao corpo docente.

Tendo como enfoque os Objetos Educacionais Digitais (OEDs), também citados por autores como Objetos de Aprendizagem (OA), a pesquisa intitulada Objetos Educacionais Digitais no processo de ensino-aprendizagem: impactos no desempenho estudantil, do pesquisador 2, tem como propósito averiguar e comparar os desempenhos de estudantes do ensino médio que fazem uso desses objetos em hiperlivros em relação àqueles que utilizam apenas o mesmo material didático impresso. A pesquisa tem como amostras objetos educacionais digitais de livros didáticos digitais do primeiro e terceiro ano do ensino médio aprovados no Programa Nacional do Livro Didático - (PNLD) 2015, o maior programa público de distribuição de livros para a educação em todo o mundo, que recentemente incluiu os didáticos digitais na Educação Básica, utilizados em escolas públicas de todo o país. No entanto, não fará distinção aos dispositivos utilizados visto que tais OEDs tem por objetivo o pleno funcionamento em todas as plataformas.

\subsection{Objetos Educacionais Digitais}

A fundamentação teórica acerca dos objetos educacionais digitais (OEDs) não atingiu ainda consolidação e precisão suficientes para um alcance completo de sua conceituação, pensando-se no significado conjunto das três palavras que compõem a terminologia. Percebe-se, no entanto, em que campo esses materiais estão inseridos, neste caso na educação com fins de melhoramentos no processo de ensinoaprendizagem, e sob qual aspecto, o digital ou eletrônico, porém nem sempre com a interação e caráter multimídia que se espera desses recursos. Já o termo "objetos" pode se referir tanto aos aspectos tangíveis quanto intangíveis de sua composição, visto sua utilização em diferentes áreas do conhecimento (GARCÍA, 2010, p. 100). Na pesquisa, por estarem inseridos em dispositivos eletrônicos, tais objetos são entendidos como recursos com alto grau de reutilização, tal qual os objetos utilizados na informática, por exemplo, em uma dialogia mais simplista com o campo da programação orientada a objetos que utiliza design patterns visando solucionar problemas de projeto com o uso de um mesmo padrão de solução a fim de não repensar e projetar novamente, aumentando a flexibilidade e capacidade de reuso (DALL'OGLIO, 2007, p. 169).

A construção de tais objetos, segundo Silva (2010), é realizada através de três equipes principais: a pedagógica, a tecnológica e a de design, todos com o mesmo objetivo e cada um com sua expertise. De maneira simplificada a autora assim descreve o processo técnico de concepção: a equipe pedagógica inicia o processo de criação de um dos objetos de aprendizagem (OA) com a escolha do conteúdo que será abordado. Essa equipe então elabora o design instrucional, trabalho realizado junto ao professor, definindo os modos de abordagem do tema, extraindo os objetivos a serem explorados, e as melhores maneiras de usufruir as potencialidades das mídias, conforme o contexto onde serão inseridos. As ideias do design instrucional precisam ser estruturadas em uma espécie de roteiro padronizado entre as equipes, para que o Objeto de Aprendizagem possa ser implementado pelos designers gráficos (equipe de design) e pelos programadores (equipe tecnológica). O roteiro é então apresentado aos demais membros do grupo e inicia-se o desenvolvimento da interface do Objeto de Aprendizagem, e a produção de seus aplicativos, imagens, simulações, entre outros. 
Segundo a Rede Interativa Virtual de Educação (RIVED) a utilização desses objetos possibilita a testagem de diferentes caminhos, o acompanhamento da evolução temporal das relações, causa e efeito, a visualização dos conceitos de diferentes pontos de vista, a comprovação de hipóteses. Animações e simulações desempenhariam a função de despertar novas ideias, capazes de relacionar conceitos, estimular a curiosidade e resolver problemas.

Dessa forma, ainda podemos adequar as categorias de OED em outra teoria definida por Bonsiepe (2011, p.87) que diz que: "é caracterizada pela interação, no sentido de apresentar informação de maneira não linear, em uma estrutura de nós semânticos ligados entre si (em rede), oferecendo alternativas para a navegação. " Voltando-se à funcionalidade dos Objetos de Aprendizagem, Lima Filho \& Waechter (2013) indicam que a missão destes objetos é explicar/ilustrar conceitos e processos, com a finalidade de reduzir a complexidade da informação, colaborando na compreensão do conteúdo.

Como objetivo geral, a pesquisa busca analisar os impactos resultantes da utilização de objetos educacionais digitais contidos em livros do tipo 1 (categorizado dessa maneira pelo PNLD por abranger as duas versões: digital e impressa; livros do tipo 2 contemplam apenas os impressos) aprovados no Programa Nacional do Livro Didático de 2015 no processo de ensino-aprendizagem de estudantes do Ensino Médio de escolas públicas do Recife, considerando, para tal análise, aspectos relacionados à Teoria da Atividade.

Especificando um pouco mais, buscou-se:

a. Identificar com base na revisão bibliográfica aspectos inerentes à aprendizagem tendo como mediadores os objetos educacionais digitais contidos em hiperlivros;

b. Elaborar estudo experimental com um livro aprovado no PNLD 2015 impresso e outro digital com o mesmo conteúdo, utilizando como meios: a criação de dois grupos focais; a observação das ações e operações relativas a leitura do conteúdo nos dois grupos; a avaliação de aprendizagem com base no conteúdo estudado e uma entrevista semiestruturada;

c. Identificar aspectos comuns e distintos na aprendizagem (internalização da informação) com um livro digital que utiliza OED e outro impresso apoiandose na Teoria da Atividade para tal análise.

\section{DESIGN, EDUCAÇÃO E TECNOLOGIA}

Para a produção do livro Design, Educação e Tecnologia, Cristina Portugal utilizou como guia da investigação o Design em situações de ensino-aprendizagem, cujo princípio básico seria a melhoria do processo de aquisição de conhecimentos com a ajuda de artefatos, ambientes e sistemas digitais e analógicos.

A obra em questão mostra discussões a respeito da cultura visual e desmaterialização no campo do Design, propondo reflexões acerca de modos de melhorar a prática de projeto no que se refere a ambientes educacionais hipermídia.

O livro publicado pela Editora Rio Books aborda ambientes hipermídias e traz para discussão as tecnologias de informação e comunicação acerca do design, tratando da interação, partindo da premissa que o design tem função social de tornar ambientes inteligíveis. 
Portugal (2013) faz uma reflexão abordando o design em situações de ensinoaprendizagem através da apresentação de um panorama educacional e onde o design é inserido em alguns momentos. Para exemplificar tal inserção, a autora utiliza algumas pesquisas brasileiras feitas utilizando essa mesma premissa, das quais destaca: "Projeto Ensina Design: a introdução de conteúdos de Design Gráfico no ensino fundamental brasileiro", "Educação através do Design - EdaDe", entre outras.

A interdisciplinaridade é vista como ponte que une Design e Educação de modo largo, incluindo o objetivo de estudar a realidade sob variados olhares e matizes. Para a autora o desafio do designer diante dessa realidade educacional observada por diferentes perspectivas é descobrir no "processo de ensino-aprendizagem, as possibilidades de intenção que acontecem entre professores, alunos, informações e conhecimentos." (PORTUGAL, 2013). Com isso, cabe ao designer desenvolver soluções para novas técnicas, métodos e materiais, visto que pesquisas o apontam como mediador do processo pedagógico.

Uma reflexão a respeito da importância da cultura visual para a área do Design é feita partindo da necessidade de estudo acerca de áreas de conhecimento relacionadas ao Design. Ainda tratando de cultura visual, a autora vê os designers como feitores da cultura visual e que esses profissionais compreendem a razão pela qual um sistema prevalece sobre outro e sob que circunstância pode mudar um sistema de representação, e quando e de que modo podem representar.

A educação das artes visuais e através dela, assim como a educação do Design e através dele, é necessária para analisar e, às vezes, colocar em julgamento a crescente e sofisticada cultura visual que vem se desenvolvendo nos ambientes hipermidiáticos.

Fica clara uma necessidade de compreender o Design contemporâneo de forma diferente, não tratando apenas do uso de novas tecnologias, pois ao fecharmos nesse contexto, restringiríamos o Design a aspectos de seus primeiros momentos, onde a identidade era limitada ao tecnicismo de projetos de artefatos.

\section{DIALOGIAS}

\subsection{Design e Arte/Educação: Uma nova perspectiva para o ensino das artes visuais nas séries iniciais do ensino fundamental}

A pesquisa buscou estudar a aplicação da união de duas metodologias, uma de Design e outra de Arte/Educação no terceiro ano de ensino fundamental de uma escola pública no interior do estado, a fim de descobrir formas de inserir o Design no conteúdo programático da disciplina de Arte, para promover a inclusão e valorização do Design no âmbito pedagógico. Defende-se o aparecimento, em primeiro lugar do problema e da conjetura, que foram testados pela observação e experimentação. Neste caso, buscou-se corroborar ou refutar a contribuição da relação entre os estudos de Arte-Educação e os fundamentos da metodologia do Design para a melhoria (ou não) do ensino das artes visuais.

Tendo como base as hipóteses apresentadas anteriormente, foi realizada, inicialmente, uma pesquisa analítica onde se apresentou a relação entre os fundamentos de arte/educação aliado as pesquisas em Design. Foi realizada também uma pesquisa exploratória para observação acerca de pontos cruciais para o ensino de Arte, com a análise de planos de aula, metodologia de ensino de arte, abordagem das artes visuais dentro do conteúdo programático na disciplina de arte e o 
desenvolvimento e elaboração dos projetos artísticos-pedagógicos desenvolvidos ao longo do ano letivo. Por último, foi realizada uma observação sistemática, onde aulas de arte foram ministradas durante um semestre do ano letivo baseadas nos princípios defendidos pela relação entre Arte/Educação e Design, e que utilizaram assemblages como artefato educacional. Havia ainda uma segunda turma (grupo de controle) onde foram aplicados os fundamentos já utilizados para o ensino de Arte na sala de aula.

Essa temática trabalhada tem uma abordagem subjetivista e visava propor uma reflexão a respeito da inclusão do Design no âmbito pedagógico. Teve como cenário de pesquisa as escolas, mais especificamente o ensino fundamental. A figura 1 demonstra a abordagem metodológica utilizada na pesquisa:

\begin{tabular}{|c|c|c|c|c|c|c|}
\hline \multicolumn{5}{|c|}{$\begin{array}{c}\text { Abordagem Subjetivista } \\
\text { na Ciência Social }\end{array}$} & \multicolumn{2}{|c|}{$\begin{array}{c}\text { Abordagem Objetivista na } \\
\text { Ciência Social }\end{array}$} \\
\hline $\begin{array}{l}\text { 1) Cerne dos } \\
\text { pressupostos } \\
\text { ontológicos }\end{array}$ & $\begin{array}{l}\text { Realidade como } \\
\text { uma projeção } \\
\text { da imaginação } \\
\text { humana }\end{array}$ & $\begin{array}{l}\text { Realidade como } \\
\text { uma construção } \\
\text { social }\end{array}$ & $\begin{array}{l}\text { Realidade como } \\
\text { um campo } \\
\text { do discurso } \\
\text { simbólico }\end{array}$ & $\begin{array}{l}\text { Realidade como } \\
\text { uma esfera } \\
\text { contextual do } \\
\text { conhecimento }\end{array}$ & $\begin{array}{l}\text { Realidade } \\
\text { como um } \\
\text { processo } \\
\text { concreto }\end{array}$ & $\begin{array}{l}\text { Realidade como } \\
\text { uma estrutura } \\
\text { concreta }\end{array}$ \\
\hline $\begin{array}{l}\text { 2) Suposições } \\
\text { sobre a } \\
\text { natureza } \\
\text { humana }\end{array}$ & $\begin{array}{l}\text { Ser humano } \\
\text { como um } \\
\text { espírito puro, } \\
\text { consciente, ser }\end{array}$ & $\begin{array}{l}\text { Ser humano } \\
\text { como um } \\
\text { construtor social, } \\
\text { a figura do } \\
\text { criador }\end{array}$ & $\begin{array}{l}\text { Ser humano } \\
\text { como um ator, a } \\
\text { figura do usuário }\end{array}$ & $\begin{array}{l}\text { Ser humano } \\
\text { como um } \\
\text { processador do } \\
\text { conhecimento }\end{array}$ & $\begin{array}{l}\text { Ser humano } \\
\text { como um } \\
\text { adaptador }\end{array}$ & $\begin{array}{l}\text { Ser humano } \\
\text { como um } \\
\text { respondedor }\end{array}$ \\
\hline $\begin{array}{l}\text { 3) Postura dos } \\
\text { fundamentos } \\
\text { epistemológicos }\end{array}$ & $\begin{array}{l}\text { Direciona para } \\
\text { obter insight } \\
\text { do fenômeno, } \\
\text { revelações }\end{array}$ & $\begin{array}{l}\text { Direciona para } \\
\text { compreender } \\
\text { como a realidade } \\
\text { social é criada }\end{array}$ & $\begin{array}{l}\text { Direciona para } \\
\text { compreender } \\
\text { padrōes do } \\
\text { discurso } \\
\text { simbólico }\end{array}$ & $\begin{array}{l}\text { Direciona para } \\
\text { traçar contextos }\end{array}$ & $\begin{array}{l}\text { Direciona } \\
\text { para o estudo } \\
\text { de sistemas, } \\
\text { processo, } \\
\text { mudanças }\end{array}$ & $\begin{array}{l}\text { Direciona para } \\
\text { construção de } \\
\text { uma ciência } \\
\text { positivista }\end{array}$ \\
\hline $\begin{array}{l}\text { 4) Algumas } \\
\text { metáforas } \\
\text { preferidas }\end{array}$ & Transcendental & $\begin{array}{l}\text { Jogo da } \\
\text { linguagem, } \\
\text { realização, texto }\end{array}$ & Teatro, cultura & Cibernética & Organismo & Máquina \\
\hline $\begin{array}{l}\text { 5) Métodos de } \\
\text { pesquisa }\end{array}$ & $\begin{array}{l}\text { Investigação } \\
\text { genuinamente } \\
\text { subjetivista }\end{array}$ & $\begin{array}{l}\text { Hermenêutica ou } \\
\text { Interpretação }\end{array}$ & $\begin{array}{l}\text { Análises } \\
\text { simbólicas }\end{array}$ & $\begin{array}{l}\text { Análise } \\
\text { contextual do } \\
\text { gestaltismo }\end{array}$ & $\begin{array}{l}\text { Análises } \\
\text { históricas }\end{array}$ & $\begin{array}{l}\text { Experimentos } \\
\text { em laboratórios } \\
\text { e levantamentos }\end{array}$ \\
\hline
\end{tabular}

Figura 1 - Quadro das abordagens metodológicas da pesquisa "Design e Arte/Educação: Uma nova perspectiva para o ensino das artes visuais nas séries iniciais do ensino fundamental". Fonte: Elaborado pelos autores, com base na tabela de Morgan \& Smircich (1980).

Vê-se na figura uma abordagem que tangencia a abordagem subjetivista, ao ter o usuário (aluno) como figura central da pesquisa, mas sem desconsiderar o contexto no qual está inserido. Além disso, tem caráter construtivista, pensando nas interações sociais para a difusão de conhecimentos.

\subsection{Objetos Educacionais Digitais no processo de ensino-aprendizagem: impactos no desempenho estudantil.}

A investigação visava responder a algumas perguntas, dentre elas:

1. OEDs trazem benefícios no processo de ensino-aprendizagem;

2. A informação contida nesses materiais é clara e bem organizada?

3. Quais aspectos (estéticos, funcionais, semânticos...) são imprescindíveis para a qualidade de um OED?

A inserção da temática sobre os impactos dos objetos educacionais digitais no desempenho de estudantes da rede pública surge da experiência profissional do pesquisador em uma empresa referência na área de tecnologia educacional. Dentre suas práticas profissionais estava a elaboração desses objetos sendo direcionados 
sobretudo às editoras, e tendo como público final estudantes em diferentes níveis escolares. Após a entrega dos materiais às editoras, pouca informação é repassada acerca do uso, aceitação e entendimento dos OEDs. Não se sabe, por exemplo, o quanto eles estão facilitando a compreensão dos alunos, sendo úteis para o aprendizado. E, mais do que isso, se conceitos ligados ao Design da Informação estão sendo aplicados, ou seja, se há uma tradução eficaz dos dados complexos, desorganizados e desestruturados, feita com conteudistas e demais educadores, em informação com valor e significado. A abordagem conferida aos estudos pode ser conferida na figura 2, a seguir:

\begin{tabular}{|c|c|c|c|c|c|c|}
\hline \multicolumn{5}{|c|}{$\begin{array}{c}\text { Abordagem Subjetivista } \\
\text { na Ciência Social }\end{array}$} & \multicolumn{2}{|c|}{$\begin{array}{c}\text { Abordagem Objetivista na } \\
\text { Ciência Social }\end{array}$} \\
\hline $\begin{array}{l}\text { 1) Cerne dos } \\
\text { pressupostos } \\
\text { ontológicos }\end{array}$ & $\begin{array}{l}\text { Realidade como } \\
\text { uma projeção } \\
\text { da imaginação } \\
\text { humana }\end{array}$ & $\begin{array}{l}\text { Realidade como } \\
\text { uma construção } \\
\text { social }\end{array}$ & $\begin{array}{l}\text { Realidade como } \\
\text { um campo } \\
\text { do discurso } \\
\text { simbólico }\end{array}$ & $\begin{array}{l}\text { Realidade } \\
\text { como uma } \\
\text { esfera } \\
\text { contextual do } \\
\text { conhecimento }\end{array}$ & $\begin{array}{l}\text { Realidade } \\
\text { como um } \\
\text { processo } \\
\text { concreto }\end{array}$ & $\begin{array}{l}\text { Realidade como } \\
\text { uma estrutura } \\
\text { concreta }\end{array}$ \\
\hline $\begin{array}{l}\text { 2) Suposições } \\
\text { sobre a natureza } \\
\text { humana }\end{array}$ & $\begin{array}{l}\text { Ser humano } \\
\text { como um espírito } \\
\text { puro, consciente, } \\
\text { ser }\end{array}$ & $\begin{array}{l}\text { Ser humano como } \\
\text { um construtor } \\
\text { social, a figura do } \\
\text { criador }\end{array}$ & $\begin{array}{l}\text { Ser humano } \\
\text { como um ator, a } \\
\text { figura do usuário }\end{array}$ & $\begin{array}{l}\text { Ser humano } \\
\text { como um } \\
\text { processador do } \\
\text { conhecimento }\end{array}$ & $\begin{array}{l}\text { Ser humano } \\
\text { como um } \\
\text { adaptador }\end{array}$ & $\begin{array}{l}\text { Ser humano } \\
\text { como um } \\
\text { respondedor }\end{array}$ \\
\hline $\begin{array}{l}\text { 3) Postura dos } \\
\text { fundamentos } \\
\text { epistemológicos }\end{array}$ & $\begin{array}{l}\text { Direciona para } \\
\text { obter insight } \\
\text { do fenômeno, } \\
\text { revelaçöes }\end{array}$ & $\begin{array}{l}\text { Direciona para } \\
\text { compreender como } \\
\text { a realidade social é } \\
\text { criada }\end{array}$ & $\begin{array}{l}\text { Direciona para } \\
\text { compreender } \\
\text { padrōes do } \\
\text { discurso } \\
\text { simbólico }\end{array}$ & $\begin{array}{l}\text { Direciona } \\
\text { para traçar } \\
\text { contextos }\end{array}$ & $\begin{array}{l}\text { Direciona } \\
\text { para o estudo } \\
\text { de sistemas, } \\
\text { processo, } \\
\text { mudanças }\end{array}$ & $\begin{array}{l}\text { Direciona para } \\
\text { construção de } \\
\text { uma ciência } \\
\text { positivista }\end{array}$ \\
\hline $\begin{array}{l}\text { 4) Algumas } \\
\text { metáforas } \\
\text { preferidas }\end{array}$ & Transcendental & $\begin{array}{l}\text { Jogo da linguagem, } \\
\text { realização, texto }\end{array}$ & Teatro, cultura & Cibernética & Organismo & Máquina \\
\hline $\begin{array}{l}\text { 5) Métodos de } \\
\text { pesquisa }\end{array}$ & $\begin{array}{l}\text { Investigação } \\
\text { genuinamente } \\
\text { subjetivista }\end{array}$ & $\begin{array}{l}\text { Hermenêutica ou } \\
\text { Interpretação }\end{array}$ & $\begin{array}{l}\text { Análises } \\
\text { simbólicas }\end{array}$ & $\begin{array}{l}\text { Análise } \\
\text { contextual do } \\
\text { gestaltismo }\end{array}$ & $\begin{array}{l}\text { Análises } \\
\text { históricas }\end{array}$ & $\begin{array}{l}\text { Experimentos } \\
\text { em laboratórios e } \\
\text { levantamentos }\end{array}$ \\
\hline
\end{tabular}

Figura 2 - Quadro das abordagens metodológicas da pesquisa “Objetos Educacionais Digitais no processo de ensino-aprendizagem: impactos no desempenho estudantil".

Fonte: Elaborado pelos autores, com base na tabela de Morgan \& Smircich (1980).

A partir do debate "subjetivo versus objetivo" analisamos as pesquisas com o intuito de encontrar as abordagens metodológicas utilizadas pelos três pesquisadores. Neste caso, a pesquisa tem uma abordagem subjetivista. Visa expor uma reflexão acerca do tema. Destaca os aspectos inerentes à concepção e os valores intrínsecos dos artefatos frente à resposta do usuário. Tem como contexto o cenário educacional e os alunos são os interpretantes com os quais se busca uma nova interpretação.

\subsection{Design, Educação e Tecnologia}

Em decorrência de uma sociedade atual plena de transformações, é clara a necessidade de abandonar um pouco as metodologias tradicionais e reavaliar as práticas docentes. De acordo com Cristina Portugal (2013), para que isso aconteça é preciso estudar e considerar o uso de novos materiais e tendências. Alguns desses estudos e questionamentos podem ser encontrados em sua obra Design, Educação $e$ Tecnologia. A abordagem conferida aos estudos da autora pode ser conferido na figura 3, a seguir: 


\begin{tabular}{|c|c|c|c|c|c|c|}
\hline \multicolumn{5}{|c|}{$\begin{array}{c}\text { Abordagem Subjetivista } \\
\text { na Ciência Social }\end{array}$} & \multicolumn{2}{|c|}{$\begin{array}{c}\text { Abordagem Objetivista na } \\
\text { Ciência Social }\end{array}$} \\
\hline $\begin{array}{l}\text { 1) Cerne dos } \\
\text { pressupostos } \\
\text { ontológicos }\end{array}$ & $\begin{array}{l}\text { Realidade como } \\
\text { uma projeção } \\
\text { da imaginação } \\
\text { humana }\end{array}$ & $\begin{array}{l}\text { Realidade como } \\
\text { uma construção } \\
\text { social }\end{array}$ & $\begin{array}{l}\text { Realidade como } \\
\text { um campo } \\
\text { do discurso } \\
\text { simbólico }\end{array}$ & $\begin{array}{l}\text { Realidade } \\
\text { como uma } \\
\text { esfera } \\
\text { contextual do } \\
\text { conhecimento }\end{array}$ & $\begin{array}{l}\text { Realidade } \\
\text { como um } \\
\text { processo } \\
\text { concreto }\end{array}$ & $\begin{array}{l}\text { Realidade como } \\
\text { uma estrutura } \\
\text { concreta }\end{array}$ \\
\hline $\begin{array}{l}\text { 2) Suposições } \\
\text { sobre a natureza } \\
\text { humana }\end{array}$ & $\begin{array}{l}\text { Ser humano } \\
\text { como um espírito } \\
\text { puro, consciente, } \\
\text { ser }\end{array}$ & $\begin{array}{l}\text { Ser humano como } \\
\text { um construtor } \\
\text { social, a figura do } \\
\text { criador }\end{array}$ & $\begin{array}{l}\text { Ser humano } \\
\text { como um ator, a } \\
\text { figura do usuário }\end{array}$ & $\begin{array}{l}\text { Ser humano } \\
\text { como um } \\
\text { processador do } \\
\text { conhecimento }\end{array}$ & $\begin{array}{l}\text { Ser humano } \\
\text { como um } \\
\text { adaptador }\end{array}$ & $\begin{array}{l}\text { Ser humano } \\
\text { como um } \\
\text { respondedor }\end{array}$ \\
\hline $\begin{array}{l}\text { 3) Postura dos } \\
\text { fundamentos } \\
\text { epistemológicos }\end{array}$ & $\begin{array}{l}\text { Direciona para } \\
\text { obter insight } \\
\text { do fenômeno, } \\
\text { revelações }\end{array}$ & $\begin{array}{l}\text { Direciona para } \\
\text { compreender como } \\
\text { a realidade social é } \\
\text { criada }\end{array}$ & $\begin{array}{l}\text { Direciona para } \\
\text { compreender } \\
\text { padrões do } \\
\text { discurso } \\
\text { simbólico }\end{array}$ & $\begin{array}{l}\text { Direciona } \\
\text { para traçar } \\
\text { contextos }\end{array}$ & $\begin{array}{l}\text { Direciona } \\
\text { para o estudo } \\
\text { de sistemas, } \\
\text { processo, } \\
\text { mudanças }\end{array}$ & $\begin{array}{l}\text { Direciona para } \\
\text { construção de } \\
\text { uma ciência } \\
\text { positivista }\end{array}$ \\
\hline $\begin{array}{l}\text { 4) Algumas } \\
\text { metáforas } \\
\text { preferidas }\end{array}$ & Transcendental & $\begin{array}{l}\text { Jogo da linguagem, } \\
\text { realização, texto }\end{array}$ & Teatro, cultura & Cibernética & Organismo & Máquina \\
\hline $\begin{array}{l}\text { 5) Métodos de } \\
\text { pesquisa }\end{array}$ & $\begin{array}{l}\text { Investigação } \\
\text { genuinamente } \\
\text { subjetivista }\end{array}$ & $\begin{array}{l}\text { Hermenêutica ou } \\
\text { Interpretação }\end{array}$ & $\begin{array}{l}\text { Análises } \\
\text { simbólicas }\end{array}$ & $\begin{array}{l}\text { Análise } \\
\text { contextual do } \\
\text { gestaltismo }\end{array}$ & $\begin{array}{l}\text { Análises } \\
\text { históricas }\end{array}$ & $\begin{array}{l}\text { Experimentos } \\
\text { em laboratórios e } \\
\text { levantamentos }\end{array}$ \\
\hline
\end{tabular}

Figura 3 - Quadro das abordagens metodológicas da pesquisa “Design, Educação e Tecnologia”. Fonte: Elaborado pelos autores, com base na tabela de Morgan \& Smircich (1980).

Percebe-se pela figura o seguimento de uma abordagem mais subjetivista, embora existam algumas características que fazem com que a pesquisa "transite" numa zona intermediária entre essa abordagem e a abordagem objetivista.

\subsection{Diálogo entre pesquisas}

A partir da explanação, estudo e análise das pesquisas, suas problemáticas e abordagens metodológicas, fica claro a similaridade teórica e acerca do problema entre os três estudos.

As pesquisas do pesquisador 2 e Cristina Portugal possuem tríade teórica estruturadas nas mesmas bases: Design, Educação e Tecnologia. Para o primeiro, o marco principal na relação entre Design e Tecnologia é o uso, visto que é através do uso que estão pautadas as problemáticas e hipóteses de sua pesquisa. Entre Design e Tecnologia é destacada a forma, enquanto o conteúdo é enaltecido no diálogo entre Design e Educação. Utilizando a tríade Design - Tecnologia - Educação e suas correlações forma - uso - conteúdo, o artefato de enfoque do pesquisador é 'Objetos Educacionais Digitais (OEDs)'.

O que difere a base teórica que estrutura a pesquisa da pesquisadora 1 das demais, é o fato de que ela não trabalha com o mesmo conceito de tecnologia que Cristina Portugal e o pesquisador 2, pois não vê tecnologia apenas do ponto de vista digital. Por essa razão a tríade teórica e estrutural dela difere-se das outras duas apresentadas, embora sejam parecidas.

Em sua pesquisa, a pesquisadora 1 escolheu como marco para a relação entre Educação e Arte, a Abordagem Triangular proposta por Ana Mae Barbosa (1998), visto que a mesma propõe um diálogo entre Arte e Educação. Entre Design e Arte foi escolhido o termo 'imersão' para permear essa associação, visto que um dos maiores objetivos pretendidos através da pesquisa é proporcionar a imersão do Design nas aulas de arte. Por fim, da ligação entre Design e Educação, o enfoque foi no termo conteúdo, sabendo que será através dele que os experimentos poderão ser executados. Do resultado dessa união, o artefato escolhido pela pesquisadora para ser 
inserido na escola foram as assemblages, por abranger características pertencentes as três áreas trabalhadas: Design, Educação e Arte.

O esquema abaixo (figura 4) busca representar graficamente as tríades e escolhas dos dois autores desse artigo, tendo como pressuposto teórico e estrutural a pesquisa de Cristina Portugal.

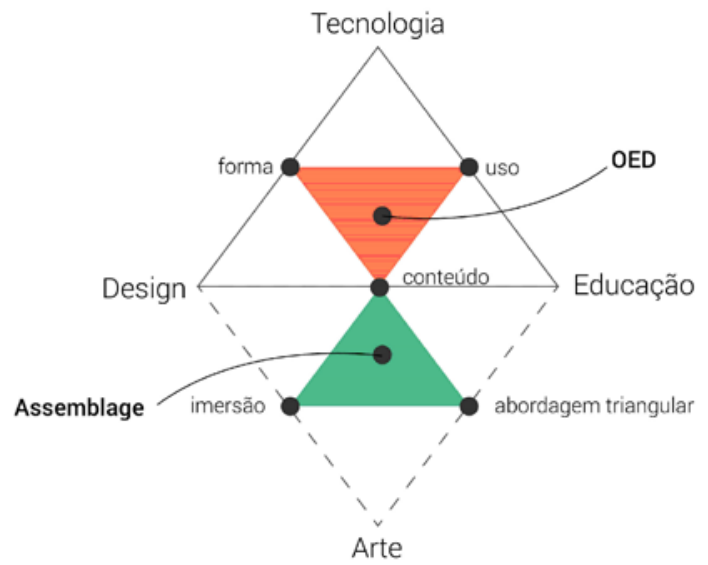

Figura 4 - Representação das Tríades teóricas e estruturais das pesquisas abordadas nesse artigo. Fonte: Elaborado pelos autores.

\section{CONSIDERAÇÕES FINAIS}

Apesar das distinções encontradas entre os objetos de estudo das três pesquisas, há entre elas diálogos que constatam determinada importância do design à educação, independente se cada um deles tem como base a utilização de artefatos analógicos ou digitais projetados para os fins de ensino-aprendizagem. É quase consensual que quando se há um projeto voltado à educação sua abordagem tangencie aspectos relacionados àquela subjetivista nas Ciências Sociais, pois lida com indivíduos e toda a comunidade a sua volta (alunos, professores, pais, orientadores pedagógicos, etc.). Essa é uma das preocupações do design: graças a sua natureza multidisciplinar projetos são pensados para o usuário e seu contexto, interagindo com diferentes aspectos que fazem parte de seu entorno. As modificações esperadas para a educação nos parecem necessárias e vemos nessa natureza multidisciplinar do design a principal característica para os passos mais significativos de tais mudanças.

\section{REFERÊNCIAS}

BARBOSA, Ana Mae Tavares de Bastos. Tópicos utópicos. Belo Horizonte: Ed. C/Arte, 1998. 198 p, il. (Arte E ensino).

BONSIEPE, Gui. Design, cultura e sociedade. São Paulo: Blucher, 2011.

DALL'OGLIO, Pablo. PHP Programando com Orientação a Objetos: Inclui Design Patterns. 1 ed. São Paulo: Novatec, 2007. 576 p.

GARCÍA, Sergio Álvarez. Uso de contenidos educativos digitales a través de sistemas de gestión del aprendizaje (LMS) y su repercusión en el acto didático comunicativo. 
2010. 1008 f. Tese (Doutorado) - Universidad Complutense de Madrid, Madrid, 2010. Disponível na internet por http em: <http://eprints.ucm.es/11631/1/T32372.pdf>. Acesso em 20 set. 2015.

LEONTIEV, Alexei. Os princípios psicológicos da brincadeira pré-escolar. In: Vygostky, L.S.; Luria, A. R; Leontiev. A. N. (Orgs.), Linguagem, desenvolvimento e aprendizagem. São Paulo: Moraes, 1994.

LÖBACH, Bernd. Design Industrial: bases para a configuração dos produtos industriais. São Paulo: Edgard Blücher, 2001.

MORIN, Edgar. Introdução ao Pensamento Complexo. Lisboa: Instituto Piaget, 1991.

LEONTIEV, Alexei et al. Linguagem, desenvolvimento e aprendizagem. São Paulo: Ícone, 1992.

LIMA FILHO, Marcos Antonio de; WAECHTER, Hans da Nóbrega. Desenvolvimento de um objeto de aprendizagem interativo para tablet. In: 60 Congresso Nacional de Ambientes Hipermídia para Aprendizagem. João Pessoa, 2013a. Disponível na internet por http em: < http://66.7.199.78/ andreenr/Anais-CONAHPA2013/assets/desenvolvimento_objeto_marcos.pdf> Acesso em 01 mai. 2016.

MORGAN, Gareth; SMIRCICH, Linda. The Case for qualitative research. Academy of Management the acdemy of management review, v. 5, n. 4, p. 491- 500, Oct. 1980. Disponível na internet por http em: <http://www.ipaa.ir/files/site1/pages/morgan\%20the\%20case\%20for\%20qualitative\% 20research.pdf>. Acesso em 01 mai. 2016.

NICOLEIT, Graziela Fátima Giacomazzo et al. Planejamento e desenvolvimento do objeto de aprendizagem regulação da liberação dos hormônios sexuais masculinos RLHSM. In: Novas Tecnologias da Educação. Disponível na internet por http em: <http://seer.ufrgs.br/renote/article/viewFile/14144/8080>. Acesso em 02 mai. 2016.

NOVA ESCOLA, São Paulo. Disponível na internet por http em: $<$ http://revistaescola.abril.com.br/fundamental-1/assemblage-arte-reunir-objetosdiversos-contar-historias-639039.shtml>. Acesso em 03 mai. 2016.

PORTUGAL, Cristina. Design, Educação e Tecnologia. Rio de Janeiro: Rio Books, 2013.

Design, educação e tecnologia (online). Rio de Janeiro: Rio Books, 2013. Disponível na internet por http em: <www.design-educacao-tecnologia.com>. Acesso em 01 mai. 2016.

RIVED. Padrões Rived. Disponível na internet por http em: <http://rived.mec.gov.br/site_objeto_lis.php>. Acesso em 03 nov. 2015.

SANTOS, Nálbia de Araújo; FARIAS, Manoel Raimundo Santana. Modelos meta-teóricos para estudos epistemológicos do processo de pesquisa acadêmica. In: 10 Congresso de Controladoria e Contabilidade, 2010, São Paulo. 10 Congresso de Controladoria e Contabilidade, 2010. Disponível na internet por http em: $<$ http://www.congressousp.fipecafi.org/web/artigos102010/138.pdf>. Acesso em 02 mai. 2016.

SILVA, Monica Renneberg. Contribuições do design para a evolução do hiperlivro do AVEA-LIBRAS: o processo de desenvolvimento de interfaces para Objetos de 
aprendizagem. 2010. 188 f. Dissertação (Mestrado) - Universidade Federal de Santa Catarina, Florianópolis, 2010. Disponível na internet por http em: < https://repositorio.ufsc.br/bitstream/

handle/123456789/103268/277986.pdf?sequence=1>. Acesso em 05 mai. 2016. 